\title{
Environmental protection for the sustainable development of tourism in Vietnam
}

\author{
Nguyen Minh Ngọc ${ }^{1 *}$, Le Minh Quang ${ }^{2}$ \\ ${ }^{1}$ Language Faculty, FPT University, Ho Chi Minh City, 700000, Vietnam. \\ ${ }^{2}$ Language Faculty, Ho Chi Minh City Open University, Ho Chi Minh City, Vietnam, 700000, \\ Vietnam.
}

\begin{abstract}
In order to develop tourism, it is impossible not to be attached to the environment, including the social-cultural and natural environment. Although identified as an important economic sector, making a great contribution to the economy, the high-speed development of the tourism industry is also creating great pressure on the environment, especially on the country's tourist destinations. If the cultural environment guarantees civilized tourism, then the natural environment is the basis for the sustainable development of tourism. Therefore, environmental protection is being posed as a vital issue in tourism today. If you do not immediately take measures to minimize plastic waste and preserve the landscape and environment, it is likely that tourists will turn their backs on Vietnamese destinations. The article mentions a few effective solutions to develop tourism in general and tourism in Vietnam in the most effective way.
\end{abstract}

\section{Introduction}

Vietnam has more than $3,000 \mathrm{~km}$ of coastline and is facing the problem of plastic waste at sea. Marine areas are facing with pollution of the marine environment at different degrees [1]. Tourism is identified as a key economic sector, in which the product of sea-island resort tourism is emphasized as a spearhead. Therefore, with localities that are the tourist focus of the province such as Sam Son, Vung Tau, Nha Trang, Phu Quoc, etc., the issue of collection and treatment of wastewater and domestic waste, and beach waste has received a lot of attention. In fact, at present, garbage collection and treatment in some beach areas are being carried out relatively effectively [2]. At the same time, the majority of households doing tourism services have committed to centralized garbage collection and use clean water and ensure food hygiene and safety in the business. Other key tourist areas are all equipped with trash cans, installed relevant signboards, and set up a garbage collection team to carry out environmental sanitation [3]. In addition, many large accommodation businesses have made environmental impact assessment reports to ensure the sustainable development of businesses and customers' interests.

In the first six months of 2019, although the number of international tourists to Vietnam continuously reached over one million visitors per month, visitors' growth rate is showing

\footnotetext{
* Corresponding author: cahoangvn@gmail.com
} 
signs of slowing down due to the Covid-19. This fact requires the tourism industry to quickly have solutions to attract international visitors, ensuring the goal of welcoming 18 million visitors in the coming years. One of the factors contributing to the decline of the tourism industry is the environmental impact [4].

In 2018, the Thai government decided to temporarily close Maya Bay to prevent damage to the natural environment, especially to save coral reefs seriously affected by tourism [5]. Previously, in 2016, this country's government also closed the island of Koh Tachai and has not announced a reopening date. At the same time, some islands located in Phuket are forced to limit the number of tourists. The closure of tourist attractions is an inevitable consequence of the hot growth in tourism, the number of tourists overloading, causing heavy pressure on the environment. However, closing is also an urgent solution to save the environment and restore marine ecosystems in order to meet the requirements of sustainable development for tourism [6].

For Vietnam, the closure of tourist sites and destinations that are heavily affected by environmental pollution has not been applied. However, many experts believe that if localities keep focusing on the number of tourists and how to make this number higher than the previous year, they should think again [3]. This is an outdated, even false, perception. Because when collecting a part of the travel budget, it must spend many times to clean the environment. That price is not low, but many places have not seen or wanted to include. Due to the number of visitors rather than the quality of visitors, the issue of the capacity of the tourist destination is being overlooked. Destination capacity can be understood simply as the ability to most effectively respond to the maximum demand of a certain number of visitors, within the limits of resources and services [7].

\section{Method}

The paper analyzes and compares data from previous and current studies to get a clear view of Vietnam's tourism situation with the desire to develop a sustainable tourism industry in the future. The article compares the number of tourists visiting tourist destinations in Vietnam and some countries to clarify the potential and inherent limitations and find more effective remedies. At the same time, the article analyzes the documents to clarify that tourism overload has a serious impact on the natural environment, so environmental protection is mentioned in order to both minimize negative impacts on natural environment and both for sustainable development.

\section{Results and discussion}

Thailand's forced closure of tourist resorts is due to a lack of concern with destination capacity. This is thought to be a worthwhile lesson for Vietnam in general and for other regions in particular. From these lessons and consequences, the environment should be seriously, responsibly, and scientifically, instead of just propagating the general form and implementation of the topside solutions. At the same time, protecting the environment for sustainable tourism development, more than ever should be identified as a central and cross-cutting task in the socio-economic development process. And therefore, from the government to the residential community and tourists, it is necessary to be aware of each party's role to take appropriate action [4].

Although the number of international visitors to Vietnam is about 8.5 million, about $7.5 \%$ is lower than in the same period in 2018. However, the number of international visitors tends to decrease gradually, typically June has the lowest level in the second half [5]. At the beginning of 2019, this figure only reached 1.18 million visitors, down $10.6 \%$ 
from the previous month. In which, visitors from Asia accounted for the largest market share in international visitors' structure to our country, down $0.4 \%$, from Australia down $6 \%$ compared to June 2018. Visitor growth in the first two quarters of the year, in general, much lower than the growth rate of $20-30 \%$ in the period of $2016-2018$. This is the reason why many people worry, the tourism industry of Vietnam is difficult to reach the target of attracting 18 million international visitors in 2019 as expected [3]. The main reason is that the number of tourists coming from China and Korea has shown signs of decrease in recent months. Statistics show that, in the first six months of the year, the number of visitors from Korea - the second-largest market in the structure of international visitors to our country reached more than two million, only a $21 \%$ increase over the same period last year (while the growth rate of the same period in 2018 reached $60.7 \%$ ). In particular, the number of tourists coming from China - Vietnam's largest international tourist market only reached nearly 2.5 million, a decrease of $3.3 \%$ compared to the first six months of 2018 (while the growth rate is the same as the period in 2018 reached $36.1 \%$ ).

The slowdown in tourism growth, not as strong as in previous years, is partly due to global trade tensions, tight monetary policy, and slower development of Asian economies. Besides, recently, countries in the region have had a fierce competition to attract international tourists with enhanced policies such as investment in advertising, product development, and strengthening the connectivity of aviation, creating favorable conditions for visas; while some destinations in our country have become saturated, leading to the dispersion of international arrivals from major source markets [8].

Recently, an advertising campaign on Vietnamese tourism in Chinese has been deployed on this country's internal social network to increase the retail customers. In the rapidly growing online travel landscape with the rise of the personalized travel trend, it is inevitable to focus on online travel [9]. To do so, the capacity to apply information technology in tourism and the linkage to create a synchronous and lively digital data system on tourism needs to be strengthened. In the past, the tourism industry heavily depended on foreign travel agencies bringing international tourists to Vietnam. This causes risks when they change direction to exploit other markets. Over the past time, Vietnam's tourism has seen the number of international tourists traveling self-sufficient through online booking so that online tourism development will be a new trend today and a trend help steady guest growth.

Statistics in the first six months of the year show that the number of visitors from Asia accounted for $77.6 \%$ of international visitors' total number. In particular, Thailand's visitors especially increased strongly with $45.4 \%$ over the same period in 2018 , showing that Vietnam is gradually asserting its position as an attractive destination for tourists in the region [4]. Therefore, besides key markets such as Korea, China, Japan, Vietnam's tourism industry needs to promote the ASEAN market's exploitation with the advantages of intraregional visa policy.

Besides, the important solution is to focus on in-depth development. In fact, over the past time, Vietnam's tourism has only focused on quantity development but has not focused much on improving quality. Although ranked sixth in the top 10 countries with the fastest growth in global tourism, the whole industry's tourism revenue is still far behind compared to neighboring countries [9].

It is determined that despite attracting many tourists, Vietnamese tourism still lacks specific products and services for tourists to be willing to spend money. The entertainment system, entertainment, and shopping spots are not synchronous and lack features, so it is not enough to stimulate the purchasing power of visitors. Therefore, the tourism industry should focus on investment in depth by improving service quality, diversifying products, and meeting tourists' diverse needs. This is also the key to reducing the pressure of hot 
growth in tourists' number on the system of environmental resources, heritage, and destinations [10].

Next, we rarely mention that the rapid increase in tourism has led to tourism activities in some beaches facing many emerging environmental and social problems. The beaches are always overload; pollution under the sea, waste on the shore, traffic jams on the road, dust, noise, etc. Traffic congestion is getting more serious, not only occurring on main roads but also spreading. On the other hand, Nha Trang city has developed many hotels and restaurants but still lacks entertainment and recreation areas. The province's tourism information is posted a lot on official and personal websites, but visitors are still confused when choosing their trip. The tour service has developed but is still not professional enough.

To develop sustainable tourism, we need to ensure development harmony between the natural environment and the social environment. We need to strengthen the application of science and technology in the tourism industry; to promote research on forecasting and impact of climate change on tourism, thereby giving appropriate development directions; to apply advanced technologies in environmental waste treatment; to use various types of energy for a chain of restaurants, hotels, tourist centers, and trade; to build a network system linking accommodation establishments with management agencies; to apply modern equipment technology to monitor in concentrated tourist places and to build software to control traffic or shopping.

With the rapid development plus the trend of tourism development in the modern digital environment, the construction of comprehensive IT application projects in the tourism industry - "smart city" is very important to meet practical requirements, contributing to the rapid development of marine tourism and an even more impressive breakthrough in the coming time [7]. Some universities in the province, research centers, information technology enterprises, and some individuals have software products for tourism; the facilities are not debatable because of the information-tour, accommodation, accommodation, etc. Only things are small, not harmonious, not a whole for easy management of the government. It is necessary to set a target to develop marine tourism in the coming time towards class and intelligence [6].

Besides, the system of restaurants, hotels, and amusement parks has sprung up quickly to meet the needs of tourists, but the control system of state management agencies and the industry has not kept up with many opportunities. The new construction service business still lacks a waste treatment system to protect the environment, making the process of environmental degradation faster [9].

In some places, many tourism businesses for the immediate benefit have exploited the destructive way of coral reefs, seafood, fishing with explosives, electric stimulation, etc. leading to the depletion of resources at sea [8]. Awareness of the people and visitors, in general, is also not high, garbage is thrown indiscriminately, especially after every Tet holiday, the garbage situation flooding tourist sites and destinations has been condemned many times but has not changed. This is one of the reasons for reducing the attractiveness, reducing the quality of tourism services, and making tourists have a bad impression on the image of Vietnamese tourism.

A lot of comments were made to improve the environment in Vietnam, including the opinion that local governments need to step in more strongly; the provincial and city government agencies direct the agencies to plan and arrange for daily-life solid waste gathering in tourist sites, cultural, historic sites and tourist accommodation establishments; Investigate and establish polluted tourist environment in the area [2]. At the same time, we need to request functional units in the area to regularly check and supervise the observance of regulations on tourism environment protection, security, and order, promptly detect and strictly handle justify the acts of violation following the provisions of law; intensify propaganda and mobilization of organizations, individuals and communities to strictly 
implement environmental protection at tourist sites and areas in their respective localities [4].

Together with other countries in the world, Vietnam is making efforts to eliminate plastic waste pollution. The target by 2020 will be to reduce the number of biodegradable plastic bags by $65 \%$ to be used in supermarkets and major commercial centers. Residents and visitors also need to change their behavior, using plastic bags, non-biodegradable, and disposable plastic products.

\section{Conclusion}

Although international visitors' growth rate to Vietnam is lower than before, it will still be significantly higher than the average growth rate of the world. The tourism industry still expects to maintain the planned visitor growth rate with the goal of welcoming more international arrivals. If the goal of tourism development becomes a key economic sector is achieved, Vietnam needs to focus on sustainable development, and environmental protection should be paid more attention. When comparing with other countries in the region, particularly Thailand, Vietnam still has a lot to learn and improve. In addition to state agencies focusing on environmental protection, tourism companies must diversify tourism products; the people also promote their awareness thoroughly and be more concerned than ever.

\section{Acknowledgements}

The author (Nguyen Minh Ngoc) would like to show thanks to FPT University where is studying. The co-author (Le Minh Quang) also likes to show thanks to Ho Chi Minh city Open University where he is taking an English course, for financial support.

\section{References}

1. Long, N. T., \& Nguyen, T. L, Sustainable development of rural tourism in an Giang Province, Vietnam. Sustainability. 10 4, 953 (2018)

2. Tuan, V. K., \& Rajagopal, P., Analyzing factors affecting tourism sustainable development towards Vietnam in the new era. European Journal of Business and Innovation Research. 7 1, 30-42 (2019).

3. Nguyen, T. Q. T., Young, T., \& Johnson, P, Tourismscapes for sustainable development: A case study in Da Nang, Vietnam. In CAUTHE 2019: Sustainability of Tourism, Hospitality \& Events in a Disruptive Digital Age: Proceedings of the 29th Annual Conference. Central Queensland University, Australia. 323, (2019).

4. Tien, N. H., Hiep, P. M., Dai, N. Q., Duc, N. M., \& Hong, T. T. K, Green entrepreneurship understanding in Vietnam. International Journal of Entrepreneurship. 24 2, 1-14 (2020).

5. Danh, N. T., \& Hoi, H. T, Effects of plastic waste to sea environment in Vietnam. In IOP Conference Series: Earth and Environmental Science. IOP Publishing, 351 , 012023 (2019).

6. Doan, N. T. K, Sustainable tourism development in Vietnam. Linking Green Productivity to Ecotourism: Experiences in the Asia-Pacific Region. Tokyo: Asian Productivity Organization Publication. 249-263(2010).

7. Hugé, J., Le Trinh, H., Hai, P. H., Kuilman, J., \& Hens, L. Sustainability indicators for clean development mechanism projects in Vietnam. Environment, Development and Sustainability, 12 4, 561-571 (2010) 
8. Le, Y., \& Hollenhorst, S, Perceptions of Vietnamese tour companies toward adopting sustainable tourism practices. Anatolia. 16 1, 79-99 (2005).

9. Parnwell, M, Tourism and natural heritage management in Vietnam and Thailand. Heritage tourism in Southeast Asia. 236-263 (2010)

10.Zhao, S. Y., \& Thong, M. P. H, Green Economy and Development Path of Vietnam. Social Science Review. 1-8 (2015). 